\title{
GEOMETRIC PROPERTIES OF MATHIEU-TYPE POWER SERIES INSIDE UNIT DISK
}

\author{
DEEPAK BANSAL AND JANUSZ SOKÓŁ
}

\begin{abstract}
In the present investigation we study normalized Mathieu-type power series and find sufficient conditions, so that the normalized Mathieu-type power series have certain geometric properties like close-to-convexity and starlikeness inside the unit disc.
\end{abstract}

Mathematics subject classification (2010): 33E20, 40A10, 30C45.

Keywords and phrases: Analytic function, univalent, starlike, close-to-convex, Mathieu series.

\section{REFERENCES}

[1] H. Alzer, J. L. Brenner And O. G. Ruehr, On Mathieu's inequality, J. Math. Anal. Appl. 218(1998) 607-610.

[2] D. BANSAL AND J. SoKóŁ, Univalency and starlikeness of Hurwitz-Lerch Zeta function inside unit disk, J. Math. Ineq. 11(3) (2017) 863-871.

[3] P. Cerone And C. T. Lenard, On integral forms of generalized Mathieu series, J. Inequal. Pure Appl. Math. 4, No. 5 (2003), Article 100, 1-11 (electronic).

[4] J. Choi And H. M. SRivastava, Mathieu series and associated sums involving the Zeta functions, Comput. Math. Appl. 592(2010) 861-867.

[5] P. H. Diananda, Some inequalities related to an inequality of Mathieu, Math. Ann. 250(1980) 9598.

[6] P. L. Duren, Univalent Functions, Springer-Verlag, 1983.

[7] N. Elezović, H. M. SRIVAstaVA AND Z. TOMOVSKI, Integral representations and integral transforms of some families of Mathieu type series, Int. Trans. Spec. Funct. 19(7-8)(2008) 481-495.

[8] O. Emersleben, Über die Reihe $\sum_{k=1}^{\infty} k\left(k^{2}+c^{2}\right)^{-2}$, Math. Ann. 125(1952) 165-171.

[9] L. FÉJER, Untersuchungen über Potenzreihen mit mehrfach monotoner Koeffizientenfolge, Acta Literarum Sci. 8(1936) 89-115.

[10] E. L. Mathieu, Traité de Physique Mathematique. VI-VII: Theory del Elasticité des corps solides (Part 2), Gauthier-Villars, Paris (1890).

[11] E. MaKai, On the inequality of Mathieu, Publ. Math. Debrecen 5(1957) 204-205.

[12] M. Nunokawa And J. SokóŁ, On an extension of Sakaguchi's result, J. Math. Ineq. 9(3)(2015) 683-697.

[13] S. Ozaki, On the theory of multivalent functions, Sci. Rep. Tokyo Bunrika Daigaku A2(1935) 167188.

[14] T. K. Pogány, H. M. SRivastava And Z. Tomovski, Some families of Mathieu a-series and alternating Mathieu a-series, Appl. Math. Comput. 173(2006) 69-108.

[15] St. Ruscheweyh And T. Sheil-Small, Hadamard product of schlicht functions and the PoylaSchoenberg conjecture, Comm. Math. Helv. 48(1973) 119-135.

[16] J. SoKó Łnd P. Witowicz, On an application of Vietoris's inequality, J. Math. Ineq. 10(3) (2016) 829-836.

[17] Z. Tomovs Ki, New integral and series representations of the generalized Mathieu series, Appl. Anal. Discrete Math. 2(2)(2008) 205-212. 